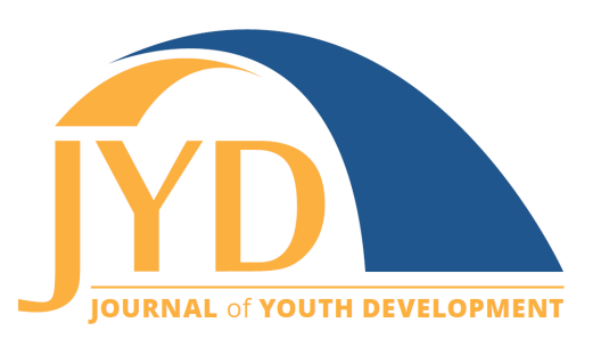

http://jyd.pitt.edu/ | Vol. 16 Issue 2-3 DOI 10.5195/jyd.2021.1042 | ISSN 2325-4017 (online)

\title{
Enhancing the International Study of Positive Youth Development: Process, Specificity, and The Sample Case of Character Virtues
}

\author{
Richard M. Lerner \\ Institute for Applied Research in Youth Development, Tufts University \\ richard.lerner@tufts.edu

\section{Pamela Jervis} \\ Institute for Fiscal Studies; Universidad de Chile; Center for Research in Inclusive Education \\ pamela_j@ifs.org.uk
}

\section{Marc H. Bornstein}

Eunice Kennedy Shriver National Institute of Child Health and Human Development; UNICEF marc.h.bornstein@gmail.com

\begin{abstract}
This article focuses on the interplay of research and practice (research $\Leftrightarrow$ practice integration) in advancing international efforts to understand and enhance positive youth development (PYD). We discuss 3 facets of PYD research and application that have cross-cutting relevance to theory, to the use of theory for designing principles of PYD programs, and to evaluating whether specific instances of youth development programs have features that promote PYD. Using dynamic, relational developmentalsystems-based concepts, we discuss the process of development involved in PYD, the use of the specificity principle to frame research and practice and, as a sample case illustrating how PYD research and practice can be advanced through the use of the specificity principle, we focus on one facet of PYD, that is, positive character, or character virtues. We point to important future directions for further illuminating the specificity of PYD process through assessing the developmental neurobiology of PYD, and we emphasize the important contributions that PYD research and practice integration can make worldwide to enhancing youth contributions to equity, social justice, and democracy.
\end{abstract}

Key words: positive youth development, relational developmental systems, character virtues development, specificity principle, youth development programs

The Positive Youth Development (PYD) perspective has taken firm hold in the mind and imagination of developmental science, both in the United States and internationally (e.g.,

(cc) EY New articles in this journal are licensed under a Creative Commons Attribution 4.0 License. This journal is published by the University Library System, University of Pittsburgh and is cosponsored by the University of Pittsburgh Press. The Journal of Youth Development is the official peer-reviewed publication of the National Association of Extension 4-H Youth Development Professionals and the National AfterSchool Association. 


\section{Enhancing the International Study of PYD}

Alvarado et al, 2017; Cabrera \& Leyendecker, 2017; Koller et al., 2019; Leman et al., 2017; Lerner et al., 2021; Petersen et al., 2017; Silbereisen \& Lerner, 2007). As Hamilton (1999) explained, beginning in the 1990s, the use of the concept of PYD and the research associated with the concept evolved into three distinguishable but integrated areas: PYD as a theory of youth development, as a set of design principles for programs or practices aimed at promoting PYD, and as instances of such PYD-promoting programs or practices. A review chapter on PYD appearing in the seventh edition of the Handbook of Child Psychology and Developmental Science (Lerner et al., 2015) was framed by this tripartite conceptualization of PYD and, in a review of PYD research and application in the decade ending in 2020 (Lerner et al., 2021), Hamilton's (1999) tripartite conception was also used to frame the PYD field both in the United States and internationally.

The purpose of the present article is not to reiterate the information in these reviews but, instead, to focus on three facets of PYD research and application that have cross-cutting relevance to theory, to the use of theory for design principles of PYD programs, and to assuring (e.g., evaluating) whether specific instances of youth development programs have features that are known to promote PYD. Here, we focus on the process of development involved in PYD because deeper understanding of this process is required for devising useful models for the development of positive features of youth development, for designing programs promoting such development, and for evaluating that these design principles are part of any specific PYD program.

This focus on process leads to a second emphasis in this article: the specificity principle (SP) (Bornstein, 2017, 2019b; Bornstein \& Suwalsky, 2021). We discuss how all extant models of the PYD process are linked to ideas associated with dynamic, relational developmental systems (RDS) metatheory ${ }^{1}$ (Overton, 2015). The key idea promoted by this metatheory is that mutually influential relations between a specific individual and the specific features of the individual's context constitute the fundamental process of human development. These relations are typically represented in the developmental science literature as individual $\Leftrightarrow$ context relations and, in RDS-based models, may also be represented as individual $\Leftrightarrow$ context coactions (Lerner, 2018b). Because these relations vary across each individual in regard to when in time they occur and in what specific context they occur, each individual's developmental process will have elements of

\footnotetext{
${ }^{1}$ A metatheory is a "theory of theories." It is a set of ideas that provide a guide to how specific theories (such as theories of PYD) should be constructed. It specifies the ideas that are essential to include in a theory.
} 


\section{Enhancing the International Study of PYD}

individual distinctiveness; there will be a person-specific, or idiographic, component to each person's life-span development. We elaborate on this idea in this article-an idea that is captured by the specificity principle (e.g., Bornstein, 2017, 2019b)—and we discuss the important role of this idea in understanding how mutually influential and mutually beneficial individual $\Leftrightarrow$ context coactions provide the basis of each young person's specific PYD pathway (see too Rose, 2016).

An important implication of the convergence between an RDS metatheory-based conception of process and the SP is that all facets of all individuals-physical/physiological, cognitive, affective, behavioral, and social-develop in accord with the specificity of the individual $\Leftrightarrow$ context relational developmental process (Bornstein, 2019b, Lerner \& Bornstein, 2021). However, we note that most research in youth development does not reflect attention to the specificity of the developmental process (e.g., see Bornstein, 2019a; Lerner, 2018b), despite appeals for such a focus by leaders of theory, research, and practice in the youth development field (Arnold \& Gagnon, 2020). A lack of adequate attention to the specificity of the developmental process leads to the third focus of this article: the development of positive (i.e., moral and prosocial; Berkowitz, 2012; Nucci, 2017) instantiations of character, an attribute of PYD that we label in this article character virtue development. Using character virtue development as a sample case, we will illustrate how the SP creates a frame for research $\Leftrightarrow$ practice integration that enhances international scholarship and application pertinent to PYD.

There are many RDS-based models of PYD (see Lerner et al., 2015 and Lerner et al., 2021 for reviews). Several of these models include a focus on such virtues in general and/or on specific character virtues as fundamental components of PYD (e.g., Benson, 2008; Damon, 2008; King et al., 2011; Lerner, 2018b; Lerner at al., 2015). Based on theory and on world events current at this writing that pertain to the importance of promoting a link between youth character virtue development and youth contributions to social justice and to the institutions of civil society and democracy, we note that, in the international study of PYD, interest in the development of character virtues is a burgeoning focus among researchers and practitioners (e.g., Banati, 2021; Lerner et al., 2019; Petersen et al., 2017; Tirrell, Gansert, et al., 2019; Tirrell, Geldhof, et al., 2019; Tirrell et al., 2020, 2021) as well as among governmental and non-governmental agencies and funders (e.g., the U.S. Agency for International Development ${ }^{2}$ [USAID], the

\footnotetext{
${ }^{2}$ www.youthpower.org/positive-youth-development-pyd-framework ; https://www.usaid.gov/faith-and-opportunity-initiatives/2020evidence-summit-strategic-religious-engagement
} 


\section{Enhancing the International Study of PYD}

Templeton World Charity Foundation, and the International Youth Foundation). Accordingly, we focus on the development of character virtues as a sample case of how an RDS-based conception of process and of specificity can enhance a vital, but as yet incompletely realized, way in which the mutually-beneficial individual $\Leftrightarrow$ context coactions involved in PYD can be enhanced around the globe.

We close this article with a discussion of important future directions for the illumination of the specificity of PYD process (regarding the developmental neurobiology of PYD and, more specifically, of character virtues) and of the importance of research $\Leftrightarrow$ practice integration in promoting equity, social justice, and democracy by enhancing PYD through youth programs.

\section{Relational Developmental Systems and the Developmental Process}

The goals of developmental science are to describe, explain, predict, and optimize individual development across the life span (Lerner, 2018a). An assumption of developmental science is that researchers and practitioners share the goal of enabling all youth to thrive. This goal is a mandate of a future international PYD movement. How is the goal to be realized or, more modestly, be increasingly better approached across time and place (Bornstein, 2019a; Parke \& Elder, 2019)? Is it even possible to promote positive development in every youth, no matter the specifics of their birth or early life experiences? To address these questions, we use RDS metatheory (Overton, 2015) to discuss the process of development involved in PYD. We then focus on Bornstein's (2017, 2019b) SP to explain how this principle is used in theory-based research and applications to advance the knowledge base needed to address these questions.

RDS metatheory emphasizes that models of human development should focus on integrated, holistic, and systematically and mutually influential (i.e., dynamic) relations across all organizational levels in the ecology of human development. These coacting levels include the biological, cognitive, emotional, and behavioral attributes of the person; social relationships; community and cultural institutions; and the physical ecology. Variables from all of these levels change interdependently across time and history (Molenaar, 2007; Overton, 2015).

These coactions shape the specific features of development of every individual, and the person's role in these coactions means that self-construction and agency are part of any RDSbased theory of development. In addition, these coactions mean that each person's behavior and development integrate specific mutually influential relations between the specific individual 


\section{Enhancing the International Study of PYD}

and the individual's specific biological, psychological, social/cultural, and physical contexts. As we have already noted, these relations may be represented as individual $\Leftrightarrow$ context coactions.

Individual $\Leftrightarrow$ context coaction means that a person is always and inextricably a physical, psychological/behavioral, and sociocultural entity (Overton, 2015; Raeff, 2016), and the specifics of the times and places of coactions for each person create person-specific (idiographic) facets of each person's life course (Elder et al., 2015; Parke \& Elder, 2019). In other words, within models of development framed by RDS metatheory, the process of development for every individual is always a specific, mutually-influential relation between the specific instances of a person's biological, psychological, and social attributes as they coact across time with the changing, specific attributes of the person's cultural world and physical ecology (Lerner, 2018a). The SP explains why such person-specific coactions must constitute the starting point for thinking about the specific process of development involved in PYD.

\section{The Specificity Principle and the PYD Process}

Whereas all development involves mutually influential coactions between a specific person and a specific context, PYD will occur only when these mutually-influential coactions are mutually beneficial (Brandtstädter, 1998; Lerner, 2018a; Lerner et al., 2015). Mutually-beneficial coactions in PYD involve a thriving young person contributing positively to the maintenance and perpetuation of a sociocultural and physical ecology that supports healthy, socially just, and equitable development of the person (Lerner, 2004). As we discuss, the concern with promoting among youth both their attributes of individual health and positive functioning (e.g., positive purpose, competence in life tasks, or confidence) and their commitment and actions directed to using these attributes to "do the right thing," to contribute positively to others and to the social good, is a key reason for increasing international interest in the PYD attribute of character virtues (see too Clement \& Bollinger, 2017; Seider et al., 2017; Templeton, 1998, 2012).

Understanding and enhancing such mutually beneficial relations may occur when researchers and practitioners collaborate in aligning specific strengths of youth (e.g., intentional selfregulations, executive functioning, or spirituality) with contextual resources needed for them to thrive (e.g., mentoring, life-skill development, opportunities for engagement with and leadership of valued community activities, and attributes of positive character, i.e., moral virtues such as generosity, empathy, humility, and commitments to truth, honesty, and justice; Berkowitz, 2012; Nucci, 2001; Peterson \& Seligman, 2004). Such specific alignment is needed 


\section{Enhancing the International Study of PYD}

for a young person to thrive as an individual and to contribute positively to civil society and to the institutions of democracy (Lerner, 2004).

The SP is the key to understanding and enhancing this mutually-beneficial individual $\Leftrightarrow$ context alignment for specific youth living at specific times and in specific places. Bornstein $(2017$, p. 5) noted:

In life-span human development, some characteristics and experiences have broad implications. Where one is born, how much education one accrues, one's gender, as examples, doubtless have pervasive consequences over the life course. Even so, as life proceeds, advantages and disadvantages cumulate to heterogeneity-so much so that variability and therefore specificity are inevitable. That is, the life-span development of specific characteristics in specific individuals is affected by specific experiences in specific ways at specific timesthis is the specificity principle. . . . The specificity principle advances a theory that is particularistic in nature.

In short, consistent within the holistic and integrated character of the developmental system, the SP emphasizes that specific contextual conditions of specific people occurring at specific times moderate specific domains of development through specific individual $\Leftrightarrow$ context coactions. The SP is core to all models of PYD (e.g., see Arnold \& Gagnon, 2020; Lerner et al., 2021). Effective youth development programs should be guided by several key questions derived from the SP:

- What about the program works? When practitioners understand the specific active components of programs, they are better able to replicate and scale programs.

- How does the program work? Being specific about the processes of individual $\Leftrightarrow$ context coactions helps practitioners increase the impact of programs and helps assure that the benefits of programs will be sustained when those programs are used in other contexts.

- For whom does the program work, and for whom does it not work? When practitioners know more about which specific youth are positively impacted, and which specific youth are not so impacted by specific PYD program components, they can scale what works for the former group of youth and implement changes for the latter group.

- Where does the program work? If practitioners can specify and understand the relevant program features that promote PYD for specific youth, they will be better able to make adjustments to programs that will also work in different settings. 


\section{Enhancing the International Study of PYD}

The use of the SP in youth development programs is burgeoning both in the United States (e.g., Arnold \& Gagnon, 2020; Bornstein \& Suwalsky, 2021; Cantor et al., 2021; Geldhof et al., 2021) and internationally (e.g., Bornstein, 2017, 2019a; Cote \& Bornstein, 2021; Esposito et al., 2021), including programs pertinent to PYD. For example, Yang and McGinley (2021) found that, among both Taiwanese and U.S. youth, development of the Five Cs of PYD involved in the Lerner and Lerner model of PYD (i.e., the Cs of competence, confidence, connection, caring, and character; Lerner, 2018a; Lerner et al., 2015) was associated with alignment between specific individuals and their specific rearing or cultural contexts.

In turn, among youth in El Salvador, Tirrell, Gansert, et al. (2019) used the SP to understand when, where, and in what ways specific enactments of a program designed to promote PYD and related constructs facilitated youth thriving more than occurred among a matched comparison group of youth. Tirrell, Gansert, et al. noted that the Bornstein (2017) SP could be used to frame within-group assessments regarding which specific youth prosper in what specific ways in which specific programs; this framing was used in data analysis from 888 Salvadoran youth (50\% female), aged 9 to 15 years, participating in the Compassion International (CI) Study of PYD (Lerner et al., 2019). The researchers compared CI-supported youth with non-CIsupported youth on nine variables: The Five CS of PYD (noted earlier) and four constructs theoretically expected to predict PYD, that is, intentional self-regulation, hopeful future expectations, and two indices of spirituality (Lerner et al, 2015). Practitioners selected 20 program sites across El Salvador that were judged to enact exemplary instantiations of CI programs aimed at promoting PYD. Whereas tests of group averages indicated no overall meaningful differences between CI youth and non-CI youth across all 20 program sites, disaggregated results from the 20 program sites presented quite a different story about CI program effectiveness: Tirrell, Gansert, et al. (2019) found that two sites showed no group differences, seven sites showed better CI-supported youth performance, three sites showed better non-CI-supported youth performance, and eight sites showed a mixed pattern. The diversity of program effectiveness enabled CI practitioners to interrogate specific individual and contextual conditions across sites that produced in specific cases specific instances of positive program effects. These facets of program effectiveness would have been masked had the SP not been used to frame this assessment.

In a follow-up assessment of CI program effects involving the above-noted indicators of thriving, Tirrell et al. (2021) longitudinally assessed 1,205 youth (mean age = 13.03 years; $49.8 \%$ female; $67.1 \%$ urban), $51 \%$ of whom were enrolled in CI-supported programs. Again, 


\section{Enhancing the International Study of PYD}

using the SP as a frame for analysis of program impacts, Tirrell et al. (2021) found evidence that reflected specificity of relations among place (program sites), time (differences across waves of longitudinal assessment,) and variables reflecting or associated with PYD.

Computations were made across several instances of specificity, including urban-rural location, gender, and CI-enrollment status. This approach enabled Tirrell and colleagues to identify program impacts that were robust across instances of specificity (and so enabling CI practitioners to understand instances of commonality or generalizability across program sites and across $\mathrm{CI}$ versus non-CI youth) and impacts unique to specific program sites or to specific groups of youth.

For instance, the researchers found commonality across gender in all analyses, but some ruralurban differences existed in intentional self-regulation (which was stronger in urban youth), and some differences between CI and non-CI youth existed at specific times of testing. Tirrell et al. (2021) found that no association between hopeful future expectations and intentional selfregulation existed among $\mathrm{CI}$ or non-CI youth at the time of initial assessment. However, at subsequent testing, this relation-which is expected to exist in programs effective in promoting PYD (e.g., Callina et al., 2014; Schmid et al., 2011)—was significant for CI youth but once again was absent among non-CI youth. In essence, then, the SP proved to be a means to explore where, when, and for which variables a PYD program had either no effect, effects that did not differentiate between program participants versus non-participants, or effects that differentiated participants from non-participants.

Therefore, the SP enables practitioners to identify if, when, and how their specific program practices/actions are associated with specific meaningful and important impacts on PYD or on theoretically associated constructs. Moreover, as illustrated in the findings of Tirrell et al. (2021) and other international research (e.g., Cote \& Bornstein, 2021), use of the SP can enable practitioners and program evaluators to identify developmental processes and/or facets of program practices that are common or generalizable across participants, program sites, and time and, as well, facets that are specific to individuals, sites, and program duration.

These uses of the SP have increasingly become foci of international efforts to understand both PYD in general and, as well, the role of other constructs in contributing to the development of PYD (such as hope for the future, intentional self-regulation, or spirituality) (e.g., Lerner, 2018b). We have noted that the study of one of the Cs included in many RDS-based models of PYD—character virtues—has become an increasing international topic of interest in programs 


\section{Enhancing the International Study of PYD}

and policies seeking to promote both youth thriving and the positive contributions of youth to civil society and democracy. We applaud this interest, and we use it as a sample case of how RDS-based models of development and, in particular, the SP can be used to improve research $\Leftrightarrow$ practice integration in an area of PYD vital to healthy youth development and to vibrant and stable institutions of civil society and democracy.

\section{The Development and Enhancement of Character Virtues}

Perhaps illustrated by the sentiment of former U.S. President, Theodore Roosevelt, to educate a person in mind and not in morals is to educate a menace to society, the growing interest in character virtue development around the world is predicated on the belief of parents, community leaders, and youth-development practitioners and researchers that enhancing the character component of PYD will benefit both individuals and civil society (Lerner 2018b; Seider et al., 2017). Of course, this belief that character development and moral beliefs and actions are linked is not new. Scholars have been interested in exploring whether the character virtues presented in Aristotle's (1999) Nicomachean Ethics (written in about 350 B.C.) are constituent attributes of thriving youth (e.g., Nucci, 2017). In addition, researchers have assessed how character fosters positive civic engagement and positive and valued contributions to communities and to the institutions of civil society (Berkowitz, 2012).

The emphasis on character virtues as involving mutually beneficial relations between individuals and their community context has also been a key basis for the growing interest in studying character development within central settings for youth development, such as families, schools, and organized, out-of-school-time (OST) activities (Vandell et al., 2015). In the United States, the promotion of character virtues is part of the social and emotional learning (SEL) framework exemplified by the Collaborative for Academic, Social, and Emotional Learning (CASEL) model (e.g., involving responsible decision making; see Durlak et al., 2011). The interest in character virtues is shared as well by practitioners working in out-of-school-time settings; the majority of school-age youth in the United States and Canada (e.g., Holt, 2015) as well as millions of youth globally participate in organized, out-of-school-time activities (e.g., sports, faith-based initiatives, or national and international programs such as 4-H or Scouting) (Lerner et al., 2018; USAID, 2013). Considerable evidence exists of the positive impact of organized, OST activities on character virtues and on character virtues-related attributes (e.g., positive purpose; kindness; generosity, or contribution to others; diligence, perseverance, or grit; and honesty, integrity, or fairness) and on several academic, social-emotional, behavioral, 


\section{Enhancing the International Study of PYD}

non-cognitive, and physical indicators of positive development that may be either moderators or covariates of character virtue development (Vandell et al., 2015).

These findings about the links between youth programs in the United States and internationally regarding character virtue development reflect commonalities in the ways in which practices such as mentoring, skill building, and opportunities for valued roles in family, school, and community settings (Lerner, 2004) may positively affect the development of the character virtue attributes of PYD. Yet, there is evidence that the use of the SP may also help practitioners understand the ways in which their actions need to align with the attributes of specific youth, in specific contexts, and at specific times in development. Examples of this SP use are studies around the world assessing the usefulness of the Lerner and Lerner RDS-based model of PYD (Lerner, 2018a, 2018b; Lerner et al., 2015).

For instance, Holsen et al. (2017) found that the way in which the Five Cs were interrelated among Norwegian youth (ages 16 to 19 ) did not correspond to interrelations existing among U.S. youth who were participants in the 4-H Study of PYD (Lerner et al., 2015). Norwegian youth appeared to distinguish between the Five Cs more strongly than U.S. youth. This finding suggests that, in specific national or cultural settings, a specific program aimed at promoting overall PYD may need to more precisely target specific Cs in specific ways in order to promote overall thriving. This implication-for the need to think about country-specific approaches to PYD programming-is underscored in the contrast of findings of Holsen et al. and Gestsdóttir et al. (2017). In comparing the usefulness of a measure of the Five Cs among U.S. youth and a sample of over 500 Icelandic adolescents, Gestsdóttir and colleagues found commonality across the two groups. In turn, a study of the Five Cs among Lithuanian youth (Erentaitè \& Raižienè, 2015) found both commonality and specificity in comparisons with U.S. youth. Specifically, the $\mathrm{C}$ of Caring seemed to have different relations with anxiety than was the case for the other Cs.

These findings again point to the utility of the SP in studies assessing commonalities and specificities in the PYD process and in the links between PYD and related constructs. Therefore, in explicit attempts to enact programs that promote positive contributions to civil society and democracy through attempts to enhance the " $C$ " of character virtues, a key recommendation would be for practitioners and program evaluators to understand how character virtues function in their specific community and cultural setting. Will a program aimed at all attributes of PYD suffice to promote positive civic engagement and contributions or are specific program actions, ones directed explicitly to character virtues-promotion, called for (Berkowitz, 2021; Berkowitz et 


\section{Enhancing the International Study of PYD}

al, 2017)? Other evidence indicates that the international community is concerned with precisely this SP-based question.

For example, UNICEF (2018) suggested that program evaluations be aimed at identifying both commonality and specificity of programs aimed at meeting one or more of United Nations (2015) Sustainable Developmental Goals (SDG):

The overarching SDG principle of leaving no one behind raises the stakes: It is no longer enough to monitor progress by global aggregates or national averages alone. Results need to be disaggregated to monitor progress . . . averages mask geographical disparities in coverage and progress. (p. 16)

Accordingly, if promoting character virtue development is critical for sustaining youth commitment to, and actions promotive of institutions of, civil society and democracy, as we believe it is, effective youth development programs pertinent to character virtue development should be guided by several key questions derived from the SP:

- How should influences on development of PYD and actual (ecologically valid) contexts (programs, families, peer group relationships) be measured?

- How should observations be designed to identify crucial relations that occur across time between a youth and the context that promotes PYD?

- What are the appropriate data analytic methods needed to ascertain if changes in positive functioning have developed and if such changes are associated with changes in the contexts of youth?

Such program evaluation reflects the vision that Banati (2021) presented for conducting research and evaluation that promotes sustainable PYD in diverse contexts, but in her view most importantly in the specific families and communities of youth. As Banati explained, "At its heart, sustainable development is about families and communities living in peace and prosperity, their children growing up safe and healthy, and transitioning to productive adulthood" (p. 1). This vision is richly illuminated by developmental research that demonstrates that each child-across all instances of his or her specific individuality-will thrive when that child is embedded in families, programs, communities, and a broader ecology of human development, that are marked by safety, resources needed for physical and mental health, and economic well-being, all equitably distributed and accessible to diverse youth and their families within a nation (Banati, 2021). Each youth then may enjoy a pathway to an adulthood involving positive contributions to self, family, community, and civil society, enhancing the link between 


\section{Enhancing the International Study of PYD}

character virtue development and positive civic engagement and civic contributions in support of civil society and democracy.

The importance of developing this link equitably and justly for global youth is not just a matter of improving youth development program practices. As evidenced by events ongoing at this writing, it is a matter of the survival of democracy and social justice in our world and of the continued existence of a habitable planet on which to live. Events in the United States and internationally that have unfolded and that continue to unfold constitute existential threats to the positive development of all youth around the world. These threats include the challenges of systemic racism, the COVID-19 pandemic, economic and health inequities and disparities, and the scientific reality of devasting global climate change (e.g., Arnold \& Gagnon, 2020; Bornstein, 2021; Ettekal \& Agans, 2020; Outley \& Blyth, 2020).

Accordingly, a case can be made that the most essential focus of youth development practice in the future is to create an inviolate connection between the process of character virtue and positive civic engagement and contributions to democracy, no matter the specificity of the steps needed to be taken in different national settings to actualize this connection. Still unaddressed issues of research $\Leftrightarrow$ practice integration will need to be examined as developmental scientists and youth development program practitioners move together to sustain this superordinate global goal. We note some of these challenges in our concluding comments.

\section{Conclusions and Future Directions}

Like the laws of physics and geometry, a universality can be found in processes of human development. No matter the nation, the community, the eras within which individuals are studied, or the periods within the life span that are assessed, the fundamental process of human development involves mutually influential individual $\Leftrightarrow$ context coactions. Another universal attribute of human development is specificity (Bornstein, 2017, 2019a, 2019b). Simply, the process that is universal, that is common to all humanity, is the same process that instantiates and enhances specific pathways across life (Rose, 2016).

Specificity is also a defining feature of the PYD process, wherein the individual $\Leftrightarrow$ context coactions of the moment are mutually beneficial to individual and context-and where specific facets of PYD, and we believe in particular character virtues, provide the link that maximizes mutual benefits between a specific individual and a specific social group, community, or nation. 


\section{Enhancing the International Study of PYD}

When seen through the RDS lens of the PYD developmental process, and the individual and contextual coactions that create specificity, researchers, practitioners, and program evaluators have a means to understand what specific attributes of what specific youth need to be aligned with what specific features of the context to produce specific outcomes of benefit to these coactions. As documented in the international PYD research that we have discussed (e.g., Cote \& Bornstein, 2021; Tirrell, Gansert, et al., 2019; Tirrell et al., 2021), this approach to the SP enables practitioners and program evaluators to learn what is common across individuals, place, and time as well as what is specific in regard to these dimensions.

However, the great promise for enhancing PYD around the world that may be found through the coupling of the RDS-approach to the PYD process and the SP-a potential that we have illustrated in the sample case of the PYD attribute of character virtues-is still incompletely actualized. RDS-based models of PYD point to the integration of variables from all levels of organization ranging from the biological to the cultural, physical ecological, and historical. To document more thoroughly what is common and what is specific across people, time, and place, all these levels of organization require much more interrogation by the international community of researchers and practitioners involved in understanding and enhancing PYD for the diverse young people of the world.

Among these levels of organization, the biological remains relatively understudied, despite recent research reviewed by Telzer et al. (in press) about implications for PYD of neurobiological development in adolescence. At the same time, this level of organization constitutes the one in which great advances in genetics, epigenetics, and neuroscience continue to excite both researchers and practitioners (e.g., Immordino-Yang et al., 2019; Slavich, 2020; Slavich \& Cole, 2013). Indeed, given our emphasis on the potential timely significance of enhancing character virtue development and its links to youth support of civil society and to the institutions of democracy, progress of neuroscience research that has implications for character virtue development may become a particularly important focus of future SP-based research and application.

For example, research identifies specific brain areas that are active when specific instances of altruism are being enacted (Baumgartner et al., 2012), when specific feelings of compassion are experienced (Engen \& Singer, 2015), when gratitude is reported (Karns et al., 2017), and when empathy is felt (Banissy et al., 2012). These and other potential connections between neurobiological development and the development of both character virtues and other facets of 


\section{Enhancing the International Study of PYD}

PYD may be more deeply explored by advances in neuroimaging techniques that allow longitudinal tracking of developmental changes in structural and functional brain organization (Casey et al., 2005; Yurgelun-Todd, 2007).

A greater exploration of brain-behavior coactions in development, if coupled with further interrogation of coactions across other levels of organization in the holistic, dynamic relational developmental system will provide new and potentially powerful resources for practitioners who-capitalizing on the specificity of these multi-level coactions-will be able to better understand how "nature is nurtured" (Immordino-Yang et al., 2019) by the design and delivery of specific features of their specific PYD programs.

We believe, then, that important opportunities exist alongside daunting challenges to use RDSbased models of the PYD process and the SP to enhance PYD programs around the world. Dynamic and specificity-attuned PYD programs can better guide and perhaps also better assure success, for evidence-based governmental and philanthropic investments aimed at enhancing the lives of specific youth and communities around the world. Broad international interest in PYD and in PYD programs has spurred the need to address global disparities in the availability of human and financial capital for enacting youth programs aimed at promoting thriving in general and, more particularly, at fostering the development of individual $\Leftrightarrow$ context coactions that enhance the propensity of the world's young people to both thrive and to be moral and ethical contributors to equitable, socially just, and democratic institutions.

Using the specific approach to researcher $\Leftrightarrow$ practitioner relations that are envisioned within a youth development field framed by RDS-based developmental concepts and, most notably, by the SP may be an impetus to focus attention and human and financial capital in a global effort to promote thriving youth and thriving communities. Such an approach to the internationalization of PYD need not be a fantasy. It is an achievable possibility, given a commitment to good science, informed practice, and possessing and acting on the will and the leadership needed worldwide to protect, defend, and enhance equity, social justice, and democracy.

\section{Acknowledgements}

The writing of this article was supported in part by the National 4-H Council, Compassion International, Templeton World Charity Foundation, the Templeton Religion Trust, and the Chan 
Zuckerberg Initiative. Additional support was provided by the Intramural Research Program of the NIH/NICHD, USA, an International Research Fellowship at the Institute for Fiscal Studies (IFS), London, UK, funded by the European Research Council (ERC) under the Horizon 2020 research and innovation programme (grant agreement No 695300-HKADeC-ERC-2015-AdG), and the Center for Research in Inclusive Education, Chile under grant PIA ANID 160009.

Correspondence to: Richard M. Lerner, Institute for Applied Research in Youth Development, Tufts University, 26 Winthrop Street, Medford, MA 02155; Email: richard.lerner@tufts.edu

\section{References}

Alvarado, G., Skinner, M., Plaut, D., Moss, C., Kapungu, C., \& Reavley, N. (2017 ). A systematic review of positive youth development programs in low- and middle-income countries. Making Cents International.

Aristotle. (1999). Nicomachean ethics (T. H. Irwin, Trans.). Indianapolis, IN: Hackett Publishing.

Arnold, M. E., \& \& Gagnon, R. J. (2020). Positive youth development theory in practice: An update on the 4-H Thriving Model. Journal of Youth Development, 15(5). https://doi.org/10.5195/jyd.2020.954

Banati, P. (Ed.). (2021). Sustainable development across the life course: Evidence from longitudinal research. Bristol, UK: Policy Press/Bristol University Press.

Banissy, M. J., Kanai, R., Walsh, V., \& Rees, G. (2012). Inter-individual differences in empathy are reflected in human brain structure. NeuroImage, 62(3), 2034-2039. https://doi.org/10.1016/j.neuroimage.2012.05.081

Baumgartner, T., Götte, L., Gügler, R., \& Fehr, E. (2012). The mentalizing network orchestrates the impact of parochial altruism on social norm enforcement. Human Brain Mapping, 33(6), 14521469. https://doi.org/10.1002/hbm.21298

Benson, P. L. (2008). Sparks: How parents can help ignite the hidden strengths of teenagers. San Francisco, CA: Jossey-Bass.

Berkowitz, M. W. (2012). Moral and character education. In K. R. Harris, S. Graham, \& T. Urdan (Eds.), APA educational psychology handbook: Individual differences and contextual factors (Vol. 2, pp. 247-264). Washington, DC: American Psychological Association.

Berkowitz, M. W. (2021). PRIMED for character education: Six design principles for school improvement. New York, NY: Routledge.

Berkowitz, M. W., Bier, M. C., \& McCauley, B. (2017). Toward a science of character education: Frameworks for identifying and implementing effective practices. Journal of Character Education, 13(1), 33-51. 
Journal of Youth Development | http://jyd.pitt.edu/ | Vol. 16 Issue 2-3 DOI 10.5195/jyd.2021.1042

Enhancing the International Study of PYD

Bornstein, M. H. (2017). The specificity principle in acculturation science. Perspectives on Psychological Science, 12, 3-45. https://doi.org/10.1177/1745691616655997

Bornstein, M. H. (2019a). A developmentalist's viewpoint: "It's about time!" Ecological systems, transaction, and specificity as key developmental principles in children's changing worlds. In R. D. Parke \& G. H. Elder, Jr. (Eds.), Children in changing worlds: Sociocultural and temporal perspectives (pp. 277-286). New York: Cambridge University Press.

Bornstein, M. H. (2019b). Fostering optimal development and averting detrimental development: Prescriptions, proscriptions, and specificity. Applied Developmental Science, 23(4), 340-345.

Bornstein, M. H. (Ed.). (2021). Psychological insights for understanding COVID-19 and families, parents, and children. New York, NY: Routledge. https://www.routledge.com/Psychological-Insights-forUnderstanding-COVID-19/book-series/COVID

Bornstein, M. H., \& Suwalsky, J. T. D. (2021). The specificity principle in adoption. Journal of Applied Developmental Psychology. https://doi.org/10.1016/j.appdev.2021.101264

Brandtstädter, J. (1998). Action perspectives on human development. In W. Damon (Series Ed.) \& R. M. Lerner (Vol. Ed.), Handbook of child psychology. Theoretical models of human development $\left(5^{\text {th }}\right.$ ed., Vol. 1, pp. 807-863). Hoboken, NJ: Wiley.

Cabrera, N. J., \& Leyendecker, B. (Eds.). (2017). Handbook on positive development of minority children and youth. Dordrecht, Netherlands: Springer.

Callina, K. S., Johnson, S., Buckingham, M., \& Lerner, R. M. (2014). Hope in context: Developmental profiles of trust, hopeful future expectations, and civic engagement across adolescence. Journal of Youth and Adolescence, 43(6), 869-883.

Cantor, P., Lerner, R. M., Pittman, K., Chase, P. A., \& Gomperts, N. (2021). Whole-child development, learning, and thriving: A dynamic systems approach. New York, NY: Cambridge University Press.

Casey, B. J., Tottenham, N., Liston, C., \& Durston, S. (2005). Imaging the developing brain: What have we learned about cognitive development? Trends in cognitive sciences, 9(3), 104-110. https://doi.org/10.1016/j.tics.2005.01.011

Clement, S., \& Bollinger, R. (2017). Accelerating progress: A new era of research on character development. Journal of Youth and Adolescence, 46, 1240-1245. https://doi.org/10.1007/s10964-017-0681-9

Cote, L. R., \& Bornstein, M. H. (2021). Three cultural contrasts in search of specificities and commonalities: Acculturation in Japanese, South American, and South Korean immigrant families. Journal of Applied Developmental Psychology. https://doi.org/10.1016/j.appdev.2021.101242

Damon, W. (2008). The path to purpose: Helping our children find their calling in life. New York, NY: Simon and Schuster. 
Durlak, J. A., Weissberg, R. P., Dymnicki, A. B., Taylor, R. D., \& Schellinger, K. B. (2011). The impact of enhancing students' social and emotional learning: A meta-analysis of school-based universal interventions. Child Development, 82, 405-432. https://doi.org/10.1111/j.14678624.2010.01564.x

Elder, G. H., Shanahan, M. J., \& Jennings, J. A. (2015). Human development in time and place. In M. H. Bornstein \& T. Leventhal (Eds.), Handbook of child psychology and developmental science. Ecological settings and processes in developmental systems ( $7^{\text {th }}$ ed., Vol. 4, pp. 6-54). Hoboken, NJ: Wiley.

Engen, H. G., \& Singer, T. (2015). Compassion-based emotion regulation up-regulates experienced positive affect and associated neural networks. Social Cognitive and Affective Neuroscience, 109), 1291-1301. https://doi.org/10.1093/scan/nsv008

Erentaitè, R., \& Raižienè, S. (2015). Lithuanian version of measure of positive youth development based on the Five Cs model. European Journal of Developmental Psychology, 12, 701-717. https://doi.org/10.1080/17405629.2015.1091772

Esposito, G., Raghunath, B. L., Azhari, A., Setoh, P., \& Bornstein, M. H. (2021). Predicting mother/child emotional availability in bilingual dyads: Multilevel approach to the specificity principle. Journal of Applied Developmental Psychology. https://doi:10.1016/j.appdev.2021.101241

Ettekal, A. V., \& Agans, J. P. (2020). Positive youth development through leisure: Confronting the COVID19 pandemic. Journal of Youth Development, 15(2), 1-20. https://doi.org/10.5195/jyd.2020.962

Geldhof, G. J., Flynn, E., Olsen, S., Mueller, M. K., Gandenberger, J., Witzek, D., \& Morris, K. N. (2021). Emotion regulation as an idiographic process: Modeling the impact of animal-assisted interventions on classroom behavior. Journal of Applied Developmental Psychology. https://doi.org/10.1016/j.appdev.2021.101253

Gestsdóttir, S. Geldhof, G. J., Lerner, J. V., \& Lerner, R. M. (2017). What drives positive youth development? Assessing intentional self-regulation as a central adolescent asset. International Journal of Developmental Science, 11(3-4), 69.79. https://doi.org/10.3233/DEV-160207

Hamilton, S. F. (1999). A three-part definition of youth development. Unpublished manuscript, Cornell University College of Human Ecology, Ithaca, NY.

Holsen, I., Geldhof, G. J., Larsen, T., \& Aardal, E. (2017). The five Cs of positive youth development in Norway: Assessment and associations with positive and negative outcomes. International Journal of Behavioral Development, 41, 559-569. https://doi.org/10.1177/0165025416645668

Holt, N. L. (Ed.). (2015). Positive youth development through sport (2 ${ }^{\text {nd }}$ ed.). New York, NY: Routledge. Immordino-Yang, M. H., Darling-Hammond, L., \& Krone, C. R. (2019). Nurturing nature: How brain development is inherently social and emotional, and what this means for education. Educational Psychologist, 54, 185-204. https://doi.org/10.1080/00461520.2019.1633924 
Karns, C. M., Moore, W. E., III, \& Mayr, U. (2017). The cultivation of pure altruism via gratitude: A functional MRI study of change with gratitude practice. Frontiers in Human Neuroscience, 11, 599. https://doi.org/10.3389/fnhum.2017.00599

King, P. E., Carr, D., \& Boitor, C. (2011). Religion, spirituality, positive youth development, and thriving. In R. M. Lerner, J. V. Lerner, \& J. B. Benson (Eds.), Positive youth development. Advances in child development and behavior (Vol. 41, pp. 159-193). London, England: Elsevier.

Koller, S. H., dos Santos Paludo, S., \& Araujo de Morais, N. (2019). Ecological engagement: Urie Bronfenbrenner's method to study human development. Cham, Switzerland: Springer Nature Switzerland AG.

Leman, P. J., Smith, E. P., \& Petersen, A. C. (2017). Introduction to the special section of Child Development on positive youth development in diverse and global contexts. Child Development, 88(4), 1039-1044. https://doi.org/10.1111/cdev.12860

Lerner, R. M. (2004). Liberty: Thriving and civic engagement among America's youth. Thousand Oaks, CA: Sage Publications.

Lerner, R. M. (2018a). Concepts and theories of human development (4 ${ }^{\text {th }}$ ed.). New York, NY: Routledge.

Lerner, R. M. (2018b). Character development among youth: Linking lives in time and place. International Journal of Behavioral Development, 42(2), 267-277.

Lerner, R. M., \& Bornstein, M. H. (2021). Contributions of the specificity principle to theory, research, and application in the study of human development: A view of the issues. Journal of Applied Developmental Psychology, 75(July-August), 101294. https://doi.org/10.1016/j.appdev.2021.101294

Lerner, R. M., Lerner, J. V., Bowers, E., \& Geldhof, G. J. (2015). Positive youth development and relational developmental systems. In W. F. Overton \& P. C. Molenaar (Eds.), Handbook of child psychology and developmental science. Theory and method. (7th ed., Vol. 1, pp. 607-651). Editor-in-chief: R. M. Lerner. Hoboken, NJ: Wiley.

Lerner, R. M., Lerner, J. V., Geldhof, G. J., Gestsdóttir, S., King, P. E., Sim, A. T. R., Batanova, M., Tirrell, J. M., \& Dowling, E. (2018). Studying positive youth development in different nations: Theoretical and methodological issues. In J. J. Lansford \& P. Banati (Eds.), Handbook of adolescent development research and its impact on global policy (pp. 68-83). New York, NY: Oxford University Press.

Lerner, R. M., Lerner, J. V., Murry, V. M., Smith, E. P., Bowers, E. P., Geldhof, G. J., \& Buckingham, M. H. (2021). Positive youth development in 2020: Theory, research, programs, and the promotion of social justice. Journal of Research on Adolescence. https://doi.org/10.1111/jora.12609

Lerner, R. M., Tirrell, J. M., Dowling, E. M., Geldhof, J., Gestsdóttir, S., Lerner, J. V., King, P. E., Williams, K., \& Sim, A. T. R. (2019). The end of the beginning: Evidence and absences studying PYD in a 
global context. Adolescent Research Review, 4(1), 1-14. https://doi.org/10.1007/s40894-0180093-4

Molenaar, P. C. M. (2007). On the implications of the classical ergodic theorems: Analysis of developmental processes has to focus on intra-individual variation. Developmental Psychobiology, 50, 60-69. https://doi.org/10.1002/dev.20262

Nucci, L. P. (2001). Education in the moral domain. Cambridge, UK: Cambridge University Press.

Nucci, L. (2017). Character: A multi-faceted developmental system. Journal of Character Education, $13(1), 1-16$.

Outley, C. W., \& Blyth, D. A. (2020). Race, antiracism, and youth development: From awareness to sustained action. Journal of Youth Development, 15(5). https://doi.org/10.5195/jyd.2020.1005

Overton, W. F. (2015). Process and relational developmental systems. In W. F. Overton \& P. C. M. Molenaar (Eds.), Handbook of child psychology and developmental science. Theory and method (7th ed., Vol. 1, pp. 9-62). Editor-in-chief: R. M. Lerner. Hoboken, NJ: Wiley.

Parke, R. D., \& Elder, Jr., G. H. (Eds.). (2019). Children in changing worlds: Sociocultural and temporal perspectives. New York, NY: Cambridge University Press.

Petersen, A. C., Koller, S. H., Motti-Stefanidi, F., \& Verma, S. (Eds.). (2017). Positive youth development in global contexts and social and economic change. Routledge.

Peterson, C., \& Seligman, M. E. P. (2004). Character strengths and virtues: A handbook and classification. Washington, D.C.: American Psychological Association.

Raeff, C. (2016). Exploring the dynamics of human development: An integrative approach. New York: Oxford University Press.

Rose, T. (2016). The end of average: How we succeed in a world that values sameness. New York: HarperCollins Publishers.

Schmid, K. L., Phelps, E., Kiely, M. K., Napolitano, C. M., Boyd, M. J., \& Lerner, R. M. (2011). The role of adolescents' hopeful futures in predicting positive and negative developmental trajectories: Findings from the 4-H study of positive youth development. The Journal of Positive Psychology, 6(1), 45-56. https://doi.org/10.1080/17439760.2010.536777

Seider, S., Jayawickreme, E., \& Lerner, R. M. (Eds.). (2017). Theoretical and empirical bases of character development in adolescence: A view of the issues. Journal of Youth in Adolescence, 46(6), 11491245. https://doi.org/10.1007/s10964-017-0650-3

Silbereisen, R. K., \& Lerner, R. M. (Eds.). (2007). Approaches to positive youth development. Thousand Oaks, CA: Sage Publications.

Slavich, G. M. (2020). Social safety theory: A biologically based evolutionary perspective on life stress, health, and behavior. Annual Review of Clinical Psychology, 16, 256-295. https://doi.org/10.1146/annurev-clinpsy-032816-045159 
Slavich, G. M., \& Cole, S. W. (2013). The emerging field of human social genomics. Clinical Psychological Science, 1, 331-348. https://doi.org/10.1177/2167702613478594

Telzer, E. H., Kwon, S-J., \& Jorgensen, N. A. (in press). Neuroscience of positive youth development. In L. Crockett, G. Carlo, \& J. Schulenberg (Eds.), Handbook of adolescent and young adult development. Washington, D. C.: American Psychological Association.

Templeton, J. M. (1998). The humble approach: Scientists discover God. Radnor, PA: Templeton Foundation Press.

Templeton, J. M. (2012). The essential worldwide laws of life. Radnor, PA: Templeton Foundation Press. Tirrell, J. M., Dowling, E. M., Gansert, P., Buckingham, M., Wong, C. A., Suzuki, S., Naliaka, C., Kibbedi, P., Namurinda, E., Williams, K., Geldhof, G. J., Lerner, J. V., King, P. E., Sim, A. T. R., \& Lerner, R. M. (2020). Toward a measure for assessing features of effective youth development programs: Contextual safety and the "big three" components of positive youth development programs in Rwanda. Child \& Youth Care Forum. 49, 201-220. https://doi.org/10.1007/s10566019-09524-6

Tirrell, J. M., Gansert, P. K., Dowling, E. M., Geldhof, G. J., Lerner, J. V., King, P. E., Iraheta, G., Williams, K., Sim., A.T.R., \& Lerner, R. M. (2019). Illuminating the use of the specificity principle to go inside the black box of programs: The sample case of an El Salvador PYD program. In S. Verma, A. Petersen, \& J. Lansford (Eds.), Sustainable human development: Challenges and solutions for implementing the United Nations' Goals [Special issue]: Zeitschrift für Psychologie, 227(2), 121128. https://doi.org/10.1027/2151-2604/a000363

Tirrell, J. M., Gansert, P. K., Dowling, E. M., Williams, K., Iraheta, Lerner, J. V., King, P. E., Sim, A. T. R., \& Lerner, R. M. (2021). Interrogating ergodicity and specificity in youth development programs in El Salvador. Journal of Applied Developmental Psychology. https://doi.org/10.1016/j.appdev.2021.101243

Tirrell, J. M., Geldhof, G. J., King, P. E., Dowling, E., Sim, A., Williams, K., Iraheta, G., Lerner, J. V., \& Lerner, R. M. (2019). Measuring spirituality, hope, and thriving among Salvadoran youth: Initial findings from the Compassion International study of positive youth development. Child \& Youth Care Forum, 48, 241-268. https://doi.org/10.1007/s10566-018-9454-1

UNICEF. (2018). Progress for every child in the SDG era. Data and Analytics Section, Division of Data, Research and Policy in UNICEF HQ.

United Nations. (2015). Transforming our world: The 2030 agenda for sustainable development. https://sustainabledevelopment.un.org/post2015/transformingourworld/publication

U.S. Agency for International Development. (2013). State of the field report: Holistic, cross-sectoral youth development: USAID Youth research, evaluation and learning project. Author. 
Journal of Youth Development | http://jyd.pitt.edu/ | Vol. 16 Issue 2-3 DOI 10.5195/jyd.2021.1042

Enhancing the International Study of PYD

Vandell, D. L., Larson, R. W., Mahoney, J. L., \& Watts, T. W. (2015). Children's organized activities. In M. H. Bornstein \& T. Leventhal (Volume Eds.), Handbook of child psychology and developmental science. Ecological settings and processes (7 $7^{\text {th }}$ ed., Vol. 4, pp. 305-344). Editor-in-Chief: R. M. Lerner. Wiley.

Yang, P-J., \& McGinley, M. (2021). Commonalities and specificities of positive youth development in the U.S. and Taiwan. Journal of Applied Developmental Psychology. https://doi.org/10.1016/j.appdev.2021.101251

Yurgelun-Todd, D. (2007). Emotional and cognitive changes during adolescence. Current Opinion in Neurobiology, 17(2), 251-257. https://doi.org/10.1016/j.conb.2007.03.009 